\title{
Neurocysticercosis-related mortality in Brazil, 2000-2011: Epidemiology of a neglected neurologic cause of death
}

\author{
Francisco Rogerlândio Martins-Melo a,b , Alberto Novaes Ramos Jr. ${ }^{a}$, \\ Marta Guimarães Cavalcanti ${ }^{\mathrm{c}}$, Carlos Henrique Alencar ${ }^{\mathrm{a}}$, Jorg Heukelbach ${ }^{\mathrm{a}, \mathrm{d}, *}$ \\ a Department of Community Health, School of Medicine, Federal University of Ceará, Rua Professor Costa Mendes, 1608, Rodolfo Teófilo, 60430-140 \\ Fortaleza, CE, Brazil \\ ${ }^{\mathrm{b}}$ Federal Institute of Education, Science and Technology of Ceará, Rua Engenheiro João Alfredo, s/n, Pabussu, 61600-000 Caucaia, CE, Brazil \\ c Infectious and Parasitic Diseases Service, Clementino Fraga Filho University Hospital, Federal University of Rio de Janeiro, Rua Rodolpho Paulo Rocco, 255, \\ Cidade Universitária, 21941-913 Rio de Janeiro, RJ, Brazil \\ $\mathrm{d}$ Anton Breinl Centre for Public Health and College of Public Health, Medical and Veterinary Sciences, Division of Tropical Health and Medicine, James Cook \\ University, Townsville, OLD 4811, Australia
}

\section{A R T I C L E I N F O}

\section{Article history:}

Received 5 June 2015

Received in revised form

23 September 2015

Accepted 16 October 2015

Available online 23 October 2015

\section{Keywords:}

Neurocysticercosis

T. solium

Mortality

Epidemiology

Time trend analysis

Spatial analysis

Brazil

\begin{abstract}
A B S T R A C T
Neurocysticercosis (NCC) is an important cause of severe neurological disease mainly in low- and middleincome countries, but data on NCC mortality from endemic areas are scarce. Here we analysed the epidemiological patterns of NCC-related mortality in Brazil. We included all deaths recorded in Brazil between 2000 and 2011, in which NCC was mentioned on death certificates, either as underlying or as associated cause of death. NCC was identified in 1829/12,491,280 deaths (0.015\%), $1130(61.8 \%)$ as underlying cause, and 699 (38.2\%) as associated cause. Overall age-adjusted mortality rate for the period was 0.97 deaths $/ 1,000,000$ inhabitants (95\% confidence interval [CI]: 0.83-1.12). The highest NCC-related mortality rates were found in males, elderly, white race/colour and residents in endemic states/regions. Age-adjusted mortality rates at national level decreased significantly over time (annual percent change [APC]: $-4.7 ; 95 \%$ CI: -6.0 to -3.3 ), with a decrease in the Southeast, South and Central-West regions, and a non-significant increasing trend in the North and Northeast regions. We identified spatial and spatiotemporal high-risk mortality clusters located mainly in NCC-endemic areas. Conditions related to the nervous system were the most commonly associated causes of death when NCC was mentioned as an underlying cause, and HIV/AIDS was the main underlying cause when NCC was an associated cause. NCC is a neglected and preventable cause of severe neurologic disease and death with high public health impact in Brazil. There is a clear need to strengthen nationwide epidemiological surveillance and control for the taeniasis/cysticercosis complex.
\end{abstract}

(c) 2015 Elsevier B.V. All rights reserved.

\section{Introduction}

Neurocysticercosis (NCC) is a parasitic infection of the human central nervous system caused by the larval form (cysticerci) of the pork tapeworm Taenia solium (Carpio, 2002; WHO, 2002, 2010a). NCC is considered a neglected and poverty-related disease, with high public health and social impact in developing countries, especially in Africa, Asia and Latin America and the Caribbean (LAC)

\footnotetext{
* Corresponding author at: Department of Community Health, School of Medicine, Federal University of Ceará Rua Professor Costa Mendes, 1608, 5. andar, Bairro Rodolfo Teófilo, 60430-140 Fortaleza, Brazil.

E-mail addresses: rogerlandio@bol.com.br (F.R. Martins-Melo), heukelbach@web.de (J. Heukelbach).
}

(WHO, 2002; Del Brutto, 2014). NCC is the main preventable single cause of acquired epilepsy (Flisser et al., 2003; WHO, 2002, 2010a; Del Brutto, 2014). About 5 million cases of epilepsy worldwide are caused by NCC (Nash et al., 2013). In LAC, an estimated 75 million people live at risk of infection, with $0.45-1.35$ million people suffering from epilepsy attributable to NCC (Coyle et al., 2012). NCC is also emerging in non-endemic countries (particularly USA, Canada and European countries), due to increased migration and travelrelated exposure (Wallin and Kurtzke, 2004; Coyle et al., 2012; Del Brutto, 2012a,b, 2014).

In Brazil, the condition is endemic particularly in the Southeast, South and Central-West regions (Agapejev, 1996, 2003; Almeida and Torres, 2011). However, its public health impact throughout the country is not known, because there is neither compulsory notification, nor active disease surveillance in most states (Takayanagui 
Table 1

Epidemiological characteristics and NCC-related mortality rates (per 1,000,000 inhabitants) by sex, age group, race/colour and region of residence in Brazil, $2000-2011$.

\begin{tabular}{|c|c|c|c|c|c|c|}
\hline \multirow{3}{*}{$\begin{array}{l}\text { Variables } \\
\text { Overall }\end{array}$} & \multicolumn{2}{|c|}{ Deaths } & \multirow{3}{*}{$\begin{array}{l}\text { Crude rate }(95 \% \mathrm{CI})^{\mathrm{a}} \\
0.82(0.70-0.96)\end{array}$} & \multirow{3}{*}{$\begin{array}{l}\text { Age-adjusted rate }(95 \% \mathrm{CI})^{\mathrm{a}, \mathrm{b}} \\
0.97(0.83-1.12)\end{array}$} & \multirow{3}{*}{$\begin{array}{l}\text { CRR } \\
- \\
\end{array}$} & \multirow{3}{*}{$\begin{array}{l}p \text {-value } \\
-\end{array}$} \\
\hline & $\bar{n}$ & $\overline{\%}$ & & & & \\
\hline & 1,829 & 100.0 & & & & \\
\hline \multicolumn{7}{|l|}{ Sex } \\
\hline Male & 1,024 & 56.0 & $0.93(0.76-1.15)$ & $1.10(0.90-1.33)$ & $1.31(0.95-1.81)$ & 0.095 \\
\hline Female & 805 & 44.0 & $0.71(0.56-0.90)$ & $0.84(0.67-1.04)$ & Ref. & - \\
\hline \multicolumn{7}{|c|}{ Age group (years) ${ }^{c}$} \\
\hline $0-14$ & 16 & 0.9 & $0.02(0.01-011)$ & - & Ref. & - \\
\hline $15-29$ & 184 & 10.1 & $0.29(0.18-0.48)$ & - & $12.05(2.05-70.75)$ & $<0.001$ \\
\hline $30-39$ & 349 & 19.1 & $1.05(0.73-1.51)$ & - & $43.34(7.64-245.89)$ & $<0.001$ \\
\hline $40-49$ & 396 & 21.7 & $1.57(1.12-2.20)$ & - & $64.76(11.46-365.75)$ & $<0.001$ \\
\hline $50-59$ & 326 & 17.9 & $2.00(1.38-2.91)$ & - & $82.57(14.51-469.72)$ & $<0.001$ \\
\hline $60-69$ & 250 & 13.7 & $2.36(1.54-3.61)$ & - & $97.26(16.89-560.16)$ & $<0.001$ \\
\hline$>70$ & 305 & 16.7 & $3.72(2.53-5.47)$ & - & $153.42(26.89-875.24)$ & $<0.001$ \\
\hline \multicolumn{7}{|c|}{ Region of residence } \\
\hline North & 16 & 0.9 & $0.09(0.02-0.42)$ & $0.13(0.04-0.49)$ & Ref. & \\
\hline Northeast & 225 & 12.3 & $0.37(0.23-0.57)$ & $0.44(0.30-0.67)$ & $4.07(0.70-23.59)$ & 0.089 \\
\hline Southeast & 1,030 & 56.3 & $1.09(0.88-1.34)$ & $1.20(0.98-1.46)$ & $12.11(2.19-66.97)$ & $<0.001$ \\
\hline South & 382 & 20.9 & $1.17(0.83-1.66)$ & $1.27(0.91-1.77)$ & $13.07(2.31-73.92)$ & $<0.001$ \\
\hline Central-West & 176 & 9.6 & $1.12(0.67-1.85)$ & $1.42(0.91-2.23)$ & $12.44(2.11-73.21)$ & $<0.001$ \\
\hline \multicolumn{7}{|l|}{ Race/colour ${ }^{\mathrm{c}}$} \\
\hline White & 1,106 & 66.8 & $1.01(0.83-1.24)$ & - & Ref. & \\
\hline Black & 118 & 7.1 & $0.79(0.43-1.46)$ & - & $0.78(0.40-1.50)$ & 0.456 \\
\hline Brown & 425 & 25.7 & $0.48(0.34-0.66)$ & - & $0.47(0.32-0.70)$ & $<0.001$ \\
\hline Yellow & 5 & 0.3 & $0.29(0.03-3.24)$ & - & $0.29(0.01-6.02)$ & 0.391 \\
\hline Indigenous & 3 & 0.2 & $0.54(0.05-5.96)$ & - & $0.32(0.01-16.07)$ & 0.545 \\
\hline
\end{tabular}

CI: confidence intervals; CRR: crude rate ratio; not calculated.

a Average annual crude- and age-adjusted mortality rates (per 1,000,000 inhabitants), calculated using the average number of NCC-related deaths as a numerator and

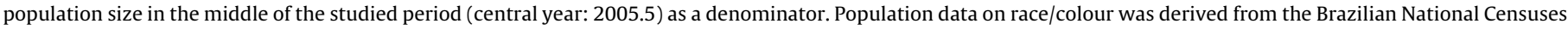
(2000 and 2010). Population size in relation to race/colour for the middle of the period was derived from an average of the 2000 and 2010 censuses.

b Age-standardized to the 2010 Brazilian population.

c Data not available in all cases (age group: 3, and race/colour: 172).

and Leite, 2001; Agapejev, 2003). In a comprehensive literature review of epidemiological data available in Brazil covering the period $1915-2002$, the frequency of NCC ranged from $0.12 \%$ to $9 \%$ in autopsies and from $0.03 \%$ to $13.4 \%$ in clinical studies (Agapejev, 2003 ). The case fatality rate of NCC ranged from $4.8 \%$ to $25.9 \%$, and asymptomatic forms of NCC were detected in $48-55 \%$ of cases with autopsy-confirmed diagnosis (Agapejev, 2003). Despite of the epidemiological, socio-economic and clinical relevance, the burden of NCC-related mortality also remains largely unknown in endemic countries (Bhattarai et al., 2013). There are very limited population-based data and few large-scale studies on NCC-related deaths (Sorvillo et al., 2004; Townes et al., 2004; Santo, 2007; Sorvillo et al., 2007). Here we present a systematic assessment of the epidemiological patterns, time trends and spatial distribution of NCC-related mortality in Brazil, from 2000 to 2011.

\section{Material and methods}

\subsection{Study area}

Brazil, South America's largest country, is extended over 8.5 million $\mathrm{km}^{2}$ with a population of about 203 million inhabitants in 2014. It is divided politically and administratively into five geographic regions (South, Southeast, Central-West, North and Northeast), 27 Federal Units (26 states and one Federal District) and 5570 municipalities (Instituto Brasileiro de Geografia e Estatística-IBGE; http://www.ibge.gov.br). There is a wide demographic, cultural and socioeconomic diversity between Brazilian regions. For instance, both North and Northeast regions comprehend the areas with the lowest income of the country. In addition, the same regions also present particular epidemiological diseaserelated patterns such as those related to poverty (Lindoso and Lindoso, 2009; Hotez and Fujiwara, 2014).

\subsection{Study design and population}

We performed a nationwide population-based study using mortality data, including time trend and spatial analyses. The study included all deaths in Brazil that occurred between 2000 and 2011, in which NCC was mentioned on the death certificates either as underlying or as associated (non-underlying) cause of death (socalled multiple causes of death) (Redelings et al., 2006; Santo, 2007). In this context, underlying cause of death is defined as the disease that initiated the events leading directly to death. For each death, only a single underlying cause is reported (WHO, 2010b; Australian Institute of Health and Welfare, 2012). Associated causes of death refer to the other conditions (immediate, intermediate and contributing causes), which intervened or significantly contributed to the death (Australian Institute of Health and Welfare, 2012).

NCC as cause of death corresponds to the B69.0 code (Cysticercosis of central nervous system [included within the category Cysticercosis-B69 code]) of the Tenth Revision of the International Statistical Classification of Diseases and Related Health Problems ICD-10) (WHO, 2010b).

\subsection{Data sources}

Mortality data were obtained from the nationwide Mortality Information System (Sistema de Informação sobre Mortalidade-SIM) of the Brazilian Ministry of Health. SIM is responsible for the collection, data entry and consolidation of death data throughout the national territory in order to allow the calculation of health indicators (Brazilian Ministry of Health, 2001). SIM datasets are generated from death certificates, which are filled out by physicians in charge, and contain demographic and clinical information. SIM data are available on public domain and freely accessible at the website of the Informatics Department of the 
Unified Health System (Departamento de Informática do Sistema Único de Saúde-DATASUS; http://tabnet.datasus.gov.br/cgi/sim/ dados/cid10_indice.htm). Downloading of the 324 mortality data sets with about 12.5 million entries, and data processing has been described in detail previously (Martins-Melo et al., 2012a,b, 2015).

Population data were obtained from the Brazilian Institute of Geography and Statistics (Instituto Brasileiro de Geografia e Estatística-IBGE, 2010), based on two censuses (2000 and 2010), and population estimates for inter-census years (2001-2009 and 2011) (IBGE; http://tabnet.datasus.gov.br/cgi/deftohtm.exe?ibge/ cnv/popuf.def).

\subsection{Variables and statistical analyses}

Variables analysed from death certificates included: sex, age, race/colour (white, black, brown [Pardo Brazilian], yellow [Asian descendant] and indigenous), place of residence (regions, states and municipalities), place of occurrence, date of death and causes of death (underlying and associated). We calculated means and standard deviations (SD) for continuous variables, and present absolute numbers and proportions with their respective 95\% confidence interval $(95 \% \mathrm{CI})$ for categorical variables.

Crude mortality rates and their 95\% CIs were calculated by sex, age group, race/colour and place of residence by dividing the number of NCC-related deaths by the population in each calendar year, expressed per 1,000,000 inhabitants. Age-adjusted rates for sex and regions/states of residence were calculated by the direct standardization method, using the Brazilian population of the 2010 Census as standard. Age categories for standardization and calculation of age-specific rates were: 0-14, 15-29, 30-39, 40-49, 50-59, $60-69$, and $\geq 70$ years. Based on the crude rates, we calculated rate ratios (RRs) with their 95\% CIs. Statistical significance of differences among groups was evaluated by the chi-squared test $(\chi 2)$. We used the Student's t-test to compare the mean age at death (in years) between groups.

Time trend analysis was performed using joinpoint regression models (Kim et al., 2000), with age-adjusted (sex and the Brazil's geographic regions) and age-specific rates as dependent variables, and the year of occurrence as independent variable. This analysis identified joinpoints via a log-linear method, where the direction or the magnitude of trends changed significantly (Kim et al., 2000). The analysis started with 0 joinpoint (a straight line without inflection points), and verified whether the inclusion of one or more joinpoints (in our analysis up to three) in the model were significant (Kim et al., 2000). Each significant joinpoint that indicated a change in the slope was retained. Statistical significance was tested using the Monte Carlo permutation test, which chooses the best segment for each model (Kim et al., 2000). The annual percent change (APC) and $95 \% \mathrm{CI}$ were calculated for each segment (Kim et al., 2000). To simplify trend comparison for the epidemiologic indicators with more than one slope, we also calculated the average annual percent change (AAPC) over the entire period. This was estimated as the geometric-weighted average of the APC, with the weights reflecting the length of each time interval segment (Kim et al., 2000). Trend was considered statistically significant when the APC and AAPC presented $p<0.05$.

We analysed the spatial distribution and spatiotemporal patterns of NCC-related mortality using the Brazilian municipalities of residence as units of analysis (territorial division of 2010). We calculated crude NCC-related mortality rates (per 100,000 inhabitants) for the 12-year study period, and the smoothed mortality rates by means of the Local Empirical Bayesian method to reduce random variations and provide greater stability of mortality rates in municipalities with small populations and rare events (Assunção et al., 1998).
We used Global Moran's I index (ranging from -1 to +1 ) to assess the presence of global spatial autocorrelation (Cliff and Ord, 1981). Then we evaluated the existence of local autocorrelation (Local Index of Spatial Association-LISA) by means of Local Moran's I index (Anselin, 1995). The objective of this procedure was to identify significant hot spots (High-High: high values spatial clusters), cold spots (Low-Low: low values spatial clusters), and spatial outliers (High-Low: high values surrounded with low value or Low-High: Low values surrounded with high values) of mortality rates (Anselin, 1995). For spatial representation of the Local Moran's index, Moran Maps were created, including municipalities with differences on $p<0.05$.

We used retrospective Kulldorff's space-time scan statistics to identify high-risk spatiotemporal clusters (Kulldorff, 1997). We used further a Poisson probability model scanning for areas of high NCC-related mortality, with a maximum spatial cluster size of $30 \%$ of the population at risk, and a maximum temporal cluster size of $50 \%$ of the study period. The most likely or primary cluster and secondary clusters were detected through the log likelihood ratio (LLR) test. We computed statistical significance using 999 Monte Carlo simulations.

We present the causes of death (diseases and disorders) that most commonly were associated with NCC-related deaths. For each death certificate that listed NCC as an underlying cause, the associated causes were examined, and for each death certificate that listed NCC as an associated cause, the underlying cause were investigated. All causes reported on the death certificates were analysed even ill-defined (classified in Chapter XVIII-R00-R99 of the ICD-10) and those characterized by the WHO as modes of death, such as cardio-respiratory arrest and multiple organ failure (Santo, 2007).

Data analysis was performed with Stata software package version 11.2 (Stata Corporation LP, College Station, TX, USA). Joinpoint regression analyses were carried out with Joinpoint Regression Program version 4.0.4 (United States National Cancer Institute, Bethesda, MD, USA). ArcGIS software version 9.3 (Environmental Systems Research Institute-ESRI, Redlands, CA, USA), and TerraView software version 4.2 (Instituto Nacional de Pesquisas Espaciais-INPE, São José dos Campos, SP, Brazil) were used for input, processing, analysis, calculation of autocorrelation indicators, and construction of thematic maps. Scan statistics were performed using SaTScan software version 9.1.1 (Harvard Medical School, Boston and Information Management Service Inc., Silver Spring, MD, USA).

\subsection{Ethics}

Analysis was based on publicly available secondary anonymous data, with no possibility of identification of individuals. The Ethical Review Board of the Federal University of Ceará (Fortaleza, Brazil) approved the study.

\section{Results}

\subsection{Neurocysticercosis-related deaths}

During 2000-2011, a total of 12,491,280 deaths were recorded in Brazil. Cysticercosis was identified on 2007 (0.016\%) death certificates (1225 as underlying cause and 782 as associated cause of death). Of these deaths, NCC was mentioned in $1829(0.015 \%$ of all deaths and $91.1 \%$ of all cysticercosis-related deaths), 1130 (61.8\%) as an underlying cause, and 699 (38.2\%) as an associated cause. The average number of NCC-related deaths was 152.4 per year $(95 \% \mathrm{CI}$ : 143.2-161.6), ranging from 132 in 2009 to 177 in 2003. 


\subsection{Epidemiological characteristics of deaths}

The predominating socio-demographic characteristics of NCCrelated deaths were: male sex (66.0\% [1024/1829), age 40-50 years (21.7\% [396/1826]), white race/colour (66.8\% [1106/1657), and residency in the Southeast region (56.3\% [1030/1829]) (Table 1). The state of São Paulo (Southeast region) had the largest proportion of deaths in the resident population (31.4\% [575/1829]). The highest proportion of deaths by age in the case of NCC as underlying cause was in the $40-50$ years-olds (24.5\% [277/1129]), and in the case as associated cause in the $\geq 70$ years-olds (24.4\% [170/697]).

The mean (SD) and median age at death of NCC-related deaths was 50.8 years ( \pm 17.4 ) and 49.1 years (range: $1.1-95.3$ ), respectively. The mean (SD) age at death in the NCC-related deaths as underlying cause was significantly lower than that for the NCCrelated deaths as associated cause $(48.3 \pm 16.6$ vs. $54.9 \pm 17.9$ years, respectively; $p<0,001$ ). The mean (SD) age at death was higher in females than in males, but not statistically significant $(51.7 \pm 18.6$ vs $50.1 \pm 16.3$ years; $p=0.055)$.

Overall, 83.3\% (1522/1827) of the NCC-related deaths occurred in hospitals, and decedent's residence was reported as place of occurrence in $13.4 \%$ (244/1827) of deaths.

\subsection{Mortality rates}

The average annual crude NCC-related mortality rate was 0.82 deaths $/ 1,000,000$ inhabitants $(95 \% \mathrm{CI}: 0.70-0.96)$ and the ageadjusted rate 0.97 deaths $/ 1,000,000$ inhabitants (95\% CI: $0.83-1.12$ ) (Table 1 ). Mortality rates increased steadily with age, with a maximum in $\geq 70$ years-olds ( 3.72 deaths/1,000,000 inhabitants) (Table 1). Age-adjusted mortality rates were higher in males than females, with no significant difference (Table 1). Individuals of white race/colour had the highest rates (Table 1 ). There was a considerable regional distribution, with the Central-West, South and Southeast regions showing highest rates (RR values $>12$, as compared to the North region) (Table 1). The highest average annual age-adjusted mortality rates by state of residence were observed in Paraná (South region, 2.38 deaths $/ 1,000,000$ inhabitants), Minas Gerais (Southeast region, 1.64 deaths/1,000,000 inhabitants), and Goiás (Central-West region, 1.59 deaths/1,000,000 inhabitants) (Fig. 1).

\subsection{Time trends}

Age-adjusted NCC-related mortality rates presented a significant decreasing trend at national level (APC: $-4.7 ; 95 \% \mathrm{CI}:-6.0$ to -3.3 .) over the 12 -year study period, with different patterns between regions (Fig. 2; Table 2). Similar to the nationwide pattern, there was a significant decrease of mortality figures in the Southeast (APC: -6.5 ; $95 \% \mathrm{CI}$ : -8.8 to -4.2 ), South (APC: $-3.4 ; 95 \% \mathrm{CI}$ : -6.7 to -0.1 ), and Central-West (APC: -6.0 ; 95\% CI: -11.0 to -0.8 ) regions. The North (APC: $5.2 ; 95 \% \mathrm{CI}:-7.8$ to 20.0 ) and Northeast (APC: $1.8 ; 95 \% \mathrm{CI}:-1.7$ to 5.4 ) regions presented a non-significant increasing trend (Fig. 2; Table 2).

Both males and females showed significant decreasing mortality trends in the study period (Table 2 ). In all age groups, mortality decreased during the observation period; the trends in the age groups 0-14 years and 40-49 years were not significant (Table 2).

\subsection{Spatial distribution and high-risk cluster analysis}

In total, $14.6 \%(813 / 5,565)$ of Brazilian municipalities in 24 of the 27 states recorded at least one NCC-related death. The spatial distribution of the average annual crude and smoothed mortality rates are presented in Fig. 3A and B, respectively. Average annual crude NCC-related mortality rates ranged among municipalities from 0.0 to 4.49 deaths $/ 100,000$ inhabitants, and smoothed mortality rates from 0 to 1.21 deaths/100,000 inhabitants. Municipalities with high NCC-related mortality rates were located mainly in states of Southeast, South and Central-West regions (Fig. 3A and B).

Global Moran's I index for the study period showed significant positive spatial autocorrelation $(0.282, p<0.001)$, evidencing the existence of spatial dependence among municipalities. Fig. 4A presents the high-risk clusters of municipalities identified according to the LISA analysis. We identified a large high-risk (High/High) concentric cluster for NCC-related mortality in central Brazil, covering several geographic regions (Fig. 4A). Clusters of municipalities with low rates (Low/Low) covered large areas in the Northeast and North regions and in small areas in the Mato Grosso and Rio Grande do Sul states (Fig. 4A).

By scan space-time analysis, we identified two significant spatiotemporal high-risk clusters in Northeast, Southeast, South and Central-West regions (Fig. 4B). The most likely cluster (primary cluster) was detected in the period 2000-2004, and included 1211 municipalities of states of Mato Grosso do Sul, Goiás, Distrito Federal, Minas Gerais, São Paulo, Paraná and Santa Catarina, with a total of 482 deaths. The relative risk was 2.66 (LLR: 142.63; $p<0.001$ ) and the annual mortality rate was 0.2 deaths/100,000 inhabitants (Fig. 4B). The secondary high-risk cluster included 709 municipalities located in the states of Bahia, Minas Gerais, Espírito Santo and Rio de Janeiro with the duration from 2002 to 2007. This cluster had 163 deaths, with a relative risk of 1.88 (LLR: $24.81 ; p<0.001$ ) and annual mortality rate 0.1 deaths/100,000 inhabitants (Fig. 4B).

\subsection{Causes of death associated to NCC-related deaths}

The main associated causes of death mentioned on death certificates in which NCC was identified as the underlying cause included nervous/neurological diseases (73.1\%), in particular intracranial hypertension, hydrocephalus and cerebral oedema (Supplementary Table 1). The second group with the highest number of mentions as associated cause were respiratory diseases (49.1\%, particularly pneumonia and respiratory failure). Sepsis and respiratory arrest were mentioned in $15.3 \%$ and $10.4 \%$ of deaths, respectively (Supplementary Table 1 ).

When NCC was mentioned as an associated cause, the most common underlying causes included cardiovascular diseases (31.5\%), infectious diseases (23.7\%) and neurological diseases (10.9\%) (Supplementary Table 2 ). HIV/AIDS (17.3\%) was the principal specific underlying cause, followed by stroke $(9.2 \%)$ and other cerebrovascular diseases (6.7\%) (Supplementary Table 2).

\section{Discussion}

To the best of our knowledge, this is the first nationwide systematic study on NCC-related mortality in Brazil. We highlighted several epidemiological and clinical aspects of the disease: we observed a decreasing trend of mortality over a 12-year period, with significant variations among Brazilian regions; we identified spatial and spatiotemporal high-risk clusters for mortality, located mainly in traditional NCC-endemic areas in the country; we described high-risk groups such as advanced age, males, individuals of white race/colour, and residents in endemic states/regions; and we described diseases of nervous and respiratory systems as the most commonly associated causes of death when NCC was the underlying cause, and HIV/AIDS as the most frequent underlying cause when NCC was listed an associated cause of death.

The age-adjusted NCC-related mortality rates presented a steady decline, caused mainly by the reduced mortality in the NCC-endemic regions, as the Southeast, South and Central-West (Agapejev, 2003). The cause of this trend may indicate a decrease 


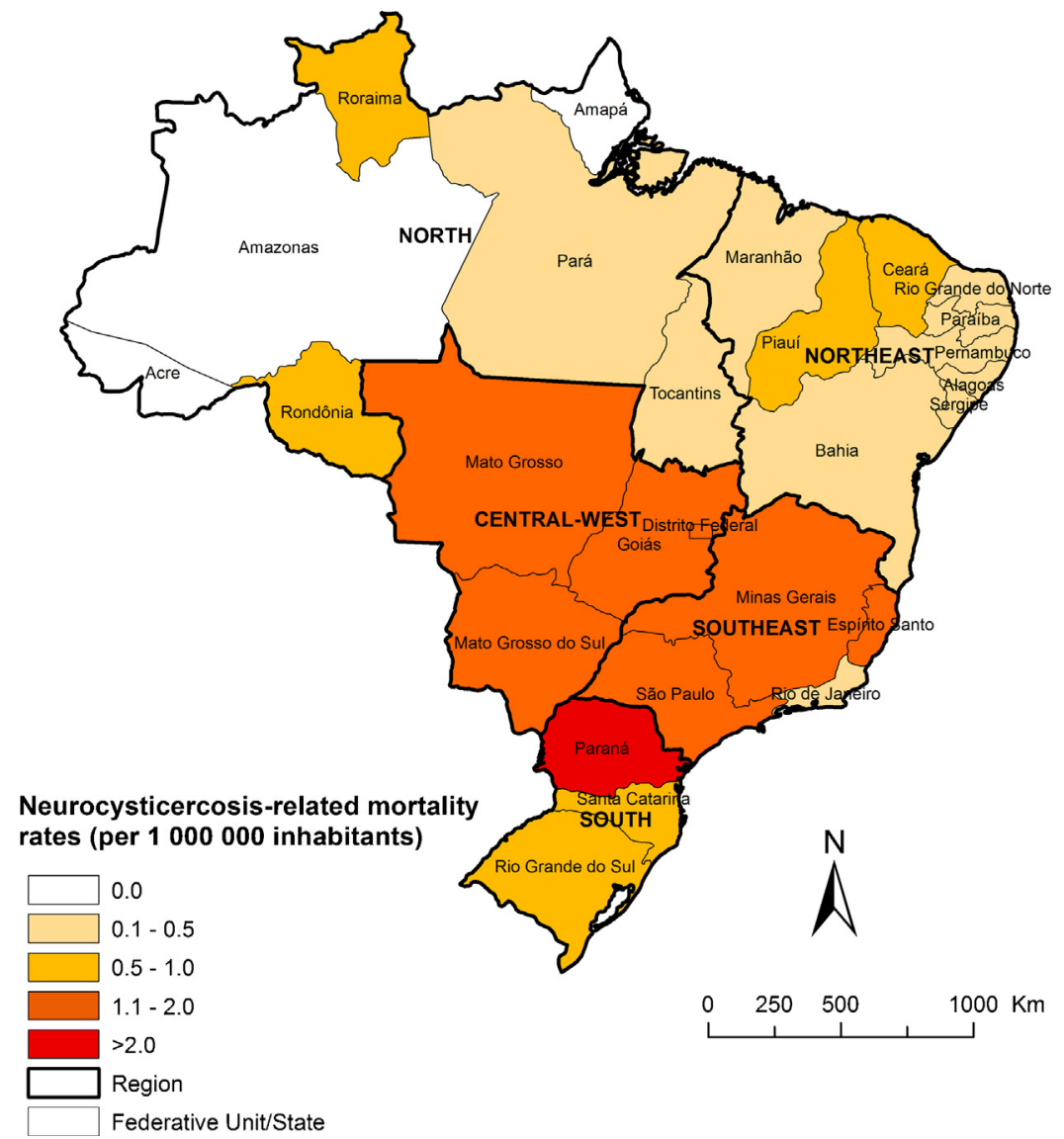

Fig. 1. Spatial distribution of average annual age-adjusted NCC-related mortality rates (per 1,000,000 inhabitants) by states of residence in Brazil, $2000-2011$.

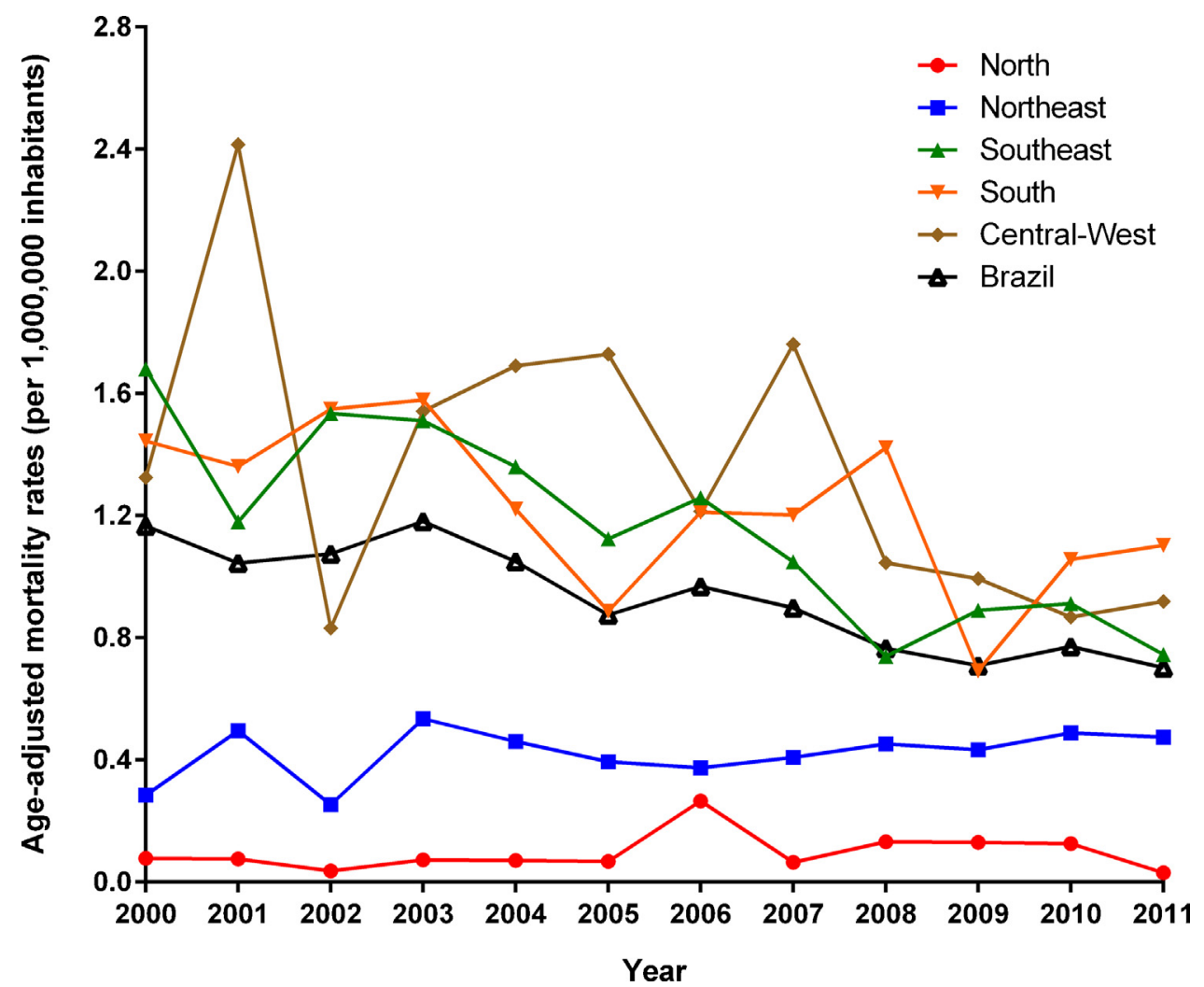

Fig. 2. Trends of age-adjusted NCC-related mortality rates (per 1,000,000 inhabitants) in Brazil and regions, 2000-2011. 
Table 2

Joinpoint regression analysis with corresponding APC of NCC-related mortality rates in Brazil, 2000-2011.

\begin{tabular}{|c|c|c|c|c|c|c|c|c|c|c|c|}
\hline \multirow[t]{2}{*}{ Variable } & \multicolumn{3}{|l|}{ Trend 1} & \multicolumn{3}{|l|}{ Trend 2} & \multicolumn{3}{|l|}{ Trend 3} & \multicolumn{2}{|c|}{ Entire period } \\
\hline & Period & $\mathrm{APC}$ & $95 \% \mathrm{CI}$ & Period & APC & $95 \% \mathrm{CI}$ & Period & APC & $95 \% \mathrm{CI}$ & AAPC & $95 \% \mathrm{CI}$ \\
\hline \multicolumn{12}{|l|}{ Sex } \\
\hline Male & 2000-2011 & $-4.6^{a}$ & -5.9 to -3.2 & & & & & & & & \\
\hline Female & 2000-2011 & $-4.8^{\mathrm{a}}$ & -7.5 to -2.0 & & & & & & & & \\
\hline \multicolumn{12}{|c|}{ Age group (years) } \\
\hline $0-14$ & 2000-2004 & -22.7 & -49.1 to 17.3 & 2004-2007 & 72.6 & -40.2 to 398.4 & 2007-2011 & $-43.9^{\mathrm{a}}$ & -66.1 to -7.2 & -14.4 & -34.3 to 11.6 \\
\hline $15-29$ & $2000-2011$ & $-6.1^{\mathrm{a}}$ & -10.0 to -2.0 & & & & & & & & \\
\hline $30-39$ & 2000-2011 & $-6.1^{\mathrm{a}}$ & -9.3 to -2.7 & & & & & & & & \\
\hline $40-49$ & $2000-2011$ & -2.7 & -6.8 to 1.5 & & & & & & & & \\
\hline $50-59$ & $2000-2011$ & $-5.5^{\mathrm{a}}$ & -8.8 to -2.1 & & & & & & & & \\
\hline $60-69$ & 2000-2011 & $-5.7^{\mathrm{a}}$ & -9.6 to -1.6 & & & & & & & & \\
\hline$\geq 70$ & 2000-2011 & $-3.2^{\mathrm{a}}$ & -5.7 to -0.7 & & & & & & & & \\
\hline \multicolumn{12}{|c|}{ Region of residence } \\
\hline North & $2000-2011$ & 5.2 & -7.8 to 20.0 & & & & & & & & \\
\hline Northeast & $2000-2011$ & 1.8 & -1.7 to 5.4 & & & & & & & & \\
\hline Southeast & $2000-2011$ & $-6.5^{\mathrm{a}}$ & -8.8 to -4.2 & & & & & & & & \\
\hline South & $2000-2011$ & $-3.4^{\mathrm{a}}$ & -6.7 to -0.1 & & & & & & & & \\
\hline Central-West & 2000-2011 & $-6.0^{\mathrm{a}}$ & -11.0 to -0.8 & & & & & & & & \\
\hline Brazil & $2000-2011$ & $-4.7^{\mathrm{a}}$ & -6.0 to -3.3 & & & & & & & & \\
\hline
\end{tabular}

APC: annual percent change; AAPC: average annual percent change; $\mathrm{CI}$ : confidence intervals.

a Significantly different from $0(p<0.05)$.
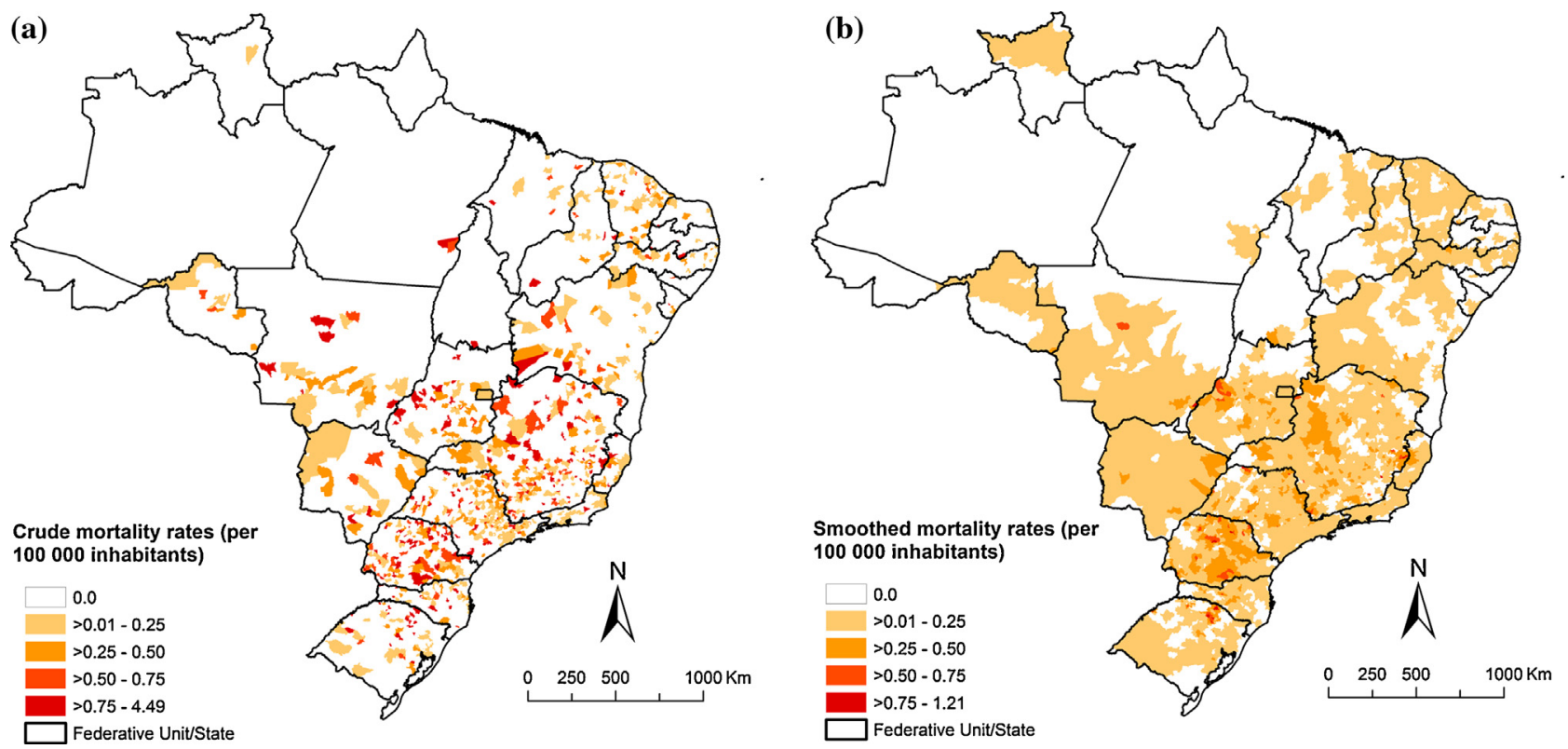

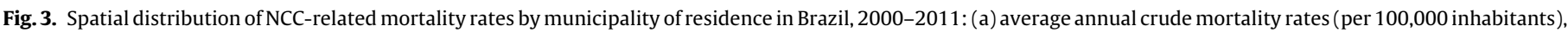
(b) average annual Bayesian-smoothed mortality rates (per 100,000 inhabitants).

in the incidence and/or case fatality rate by NCC in recent years (Santo, 2007). In the absence of systematic disease surveillance and control programs in most endemic areas, nonspecific measures, such as improved general living and sanitary conditions, improved health education and access to health services may have played an important role in reducing NCC incidence and, consequently, severe and fatal cases (Takayanagui and Leite, 2001; Santo, 2007). Furthermore, the use of better diagnostic approaches, early diagnosis and access to both clinical and surgical treatments may be important factors involved in decreased case fatality and mortality in endemic regions (Takayanagui and Leite, 2001; Santo, 2007).

A study in Mexico using national data verified an important decrease of the frequency of cases of cysticercosis and taeniasis from 1990 to 2009; the implementation of national control program for T. solium and the general improvement of living conditions in Mexico were considered as the main driving factors (Flisser and
Correa, 2010). The most socio-economically deprived regions in Brazil (North and Northeast) despite having the lowest rates, did not present a decreasing trend of NCC-related mortality in the study period. In these areas there are usually no specific control programs, there is limited access to health services, and living conditions are poor (Agapejev, 2003; WHO, 2010a; Agapejev, 2011; Del Brutto, 2014).

Our study evidenced high-risk clusters for NCC-related mortality in the well-known disease-endemic areas in Southeast, South and Central-West regions of the country. The risk was more than 12 times higher in these regions, as compared to the North region. In fact, recent evidence has shown that highest occurrence of NCC was found in some states of these regions, with occasional occurrence in some states of the Northeast region (Agapejev, 1996, 2003). Although the frequency of cases of NCC is associated with precarious sanitary conditions and low socioeconomic conditions in 

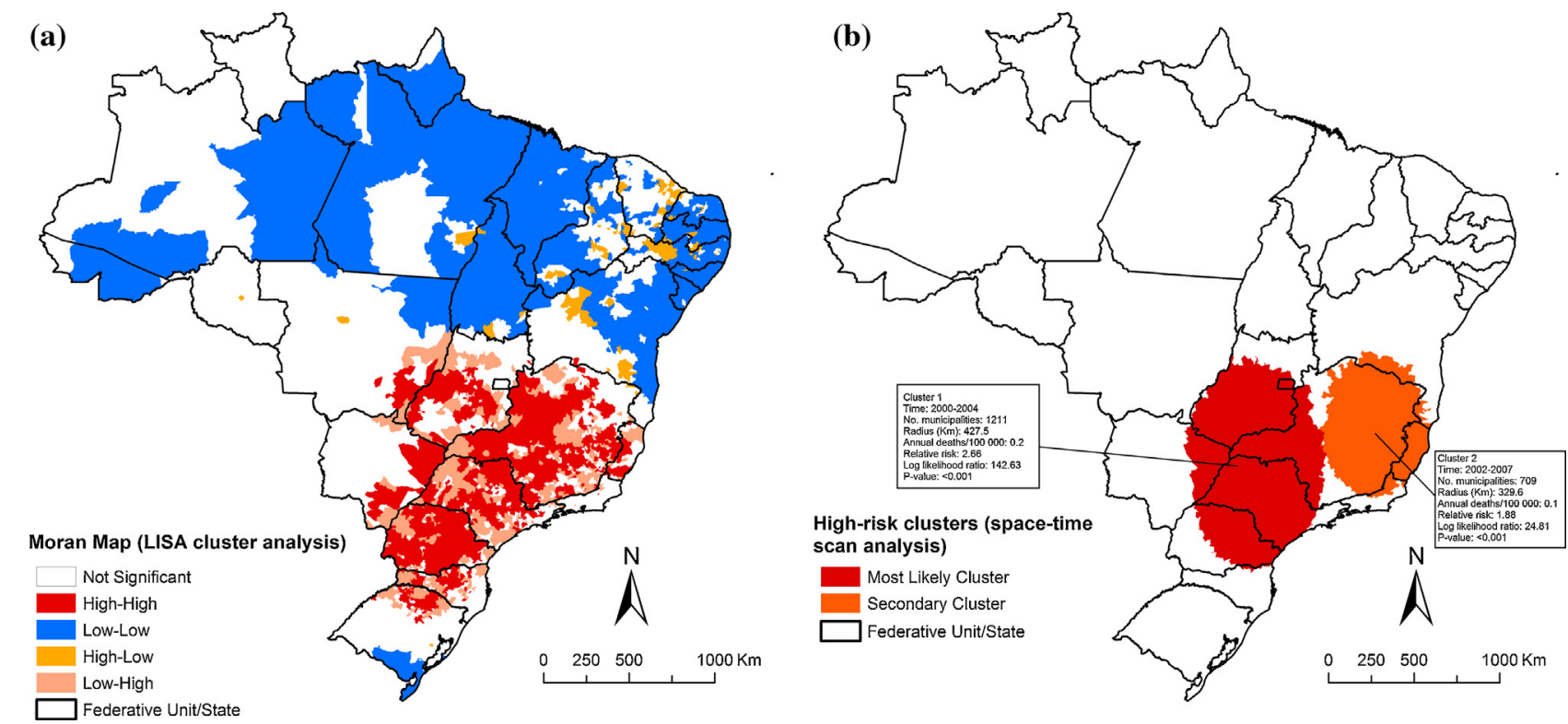

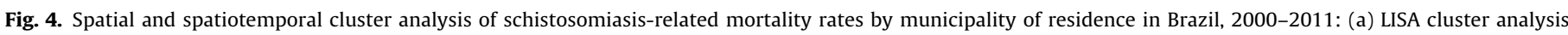
(Moran Map), (b) scan space-time clusters analysis.

endemic areas (WHO, 2010a; Agapejev, 2011), the high occurrence of the disease in South and Southeast regions may also be due to higher coverage and access to diagnosis by neuroimaging tests (computed tomography [CT] or/and Magnetic Resonance Imaging [MRI]), and clinical and surgical treatment, and the presence of specific control programs and disease notification (Pfuetzenreiter and Pires, 2000; Agapejev, 2003, 2011). The low occurrence of NCC in some areas, such as North and Northeast regions, can be explained by the lack of notification and difficulty of access to medical care and diagnostic methods, which can reduce the frequency of diagnosis and result in underreporting of the disease (Pfuetzenreiter and Pires, 2000; Agapejev, 2003). Internal migration processes, especially of people from rural areas in disease-endemic regions to urban centres, may have also affected the endemic patterns of disease in the country (Mendes et al., 2005; Benedeti et al., 2007; Gonzales et al., 2015).

The higher NCC-related mortality rates observed in males confirm findings of other large-scale mortality studies carried out in the state of São Paulo, Brazil (Santo, 2007), and in the USA (Sorvillo et al., 2004, 2007). The relationship between sex and NCC infection risk is controversial. Some studies showed a higher frequency of the disease in males (Chimelli et al., 1998; Chagas et al., 2003; LinoJunior et al., 2007; Almeida and Torres, 2011), while others showed a higher prevalence of NCC in females (Pfuetzenreiter and AvilaPires, 1999; Mendes et al., 2005; Benedeti et al., 2007; Grazziotin et al., 2010; Coral-Almeida et al., 2015). A previous literature review on NCC epidemiology in Brazil showed a higher prevalence of NCC among males, with more frequent involvement of severe manifestations in female patients (Agapejev, 2003, 2011). In fact, in studies that showed a higher frequency of NCC in males, generally most cases were considered asymptomatic (Shandera et al., 1994; Chimelli et al., 1998; Montemor Netto et al., 2000; Almeida and Torres, 2011). Studies showed that some forms of NCC are more severe in women, with a more intense inflammatory response against the parasite, indicating a possible hormonal influence on the disease development or susceptibility (Del Brutto et al., 1988; Pfuetzenreiter and Avila-Pires, 1999; Fleury et al., 2004; Mendes et al., 2005; Benedeti et al., 2007). Gender-specific healthcare seeking behaviour may also play a role. The more frequent occurrence of clinical manifestations in women would lead them to seek medical assistance more frequently and, consequently, to carry out more diagnostic testing than men (Pfuetzenreiter and Avila-Pires, 1999; Grazziotin et al., 2010).

The high NCC-related death rates among elderly reflect the patterns of chronic and debilitating nature of this disease (Croker et al., 2012). There is a longer exposure to parasites with increasing age, and probably patients are continuously infected with NCC during their lifetime (Freitas et al., 2005; Mendes et al., 2005; Cavellani et al., 2007, 2012; Coral-Almeida et al., 2015). Studies have demonstrated that older people are more tolerant to the parasite than younger, with NCC less symptomatic in older people than in younger people (Cavellani et al., 2007, 2012). Some studies have indicated higher levels of active infection in elderly people, which was suggested to be due to a lowered host immune response (Praet et al., 2010; Secka et al., 2011; Mwape et al., 2013). This could indicate that susceptibility to become infected increases with age, whereas there is a decrease of resistance against severe disease (Cavellani et al., 2012). These effects may explain higher mean age at death and higher proportion of deaths in older age groups for NCC as an associated cause when compared to NCC as an underlying cause, which had higher predominance of deaths in middle-aged adults. The simultaneous occurrence of common chronic diseases in the elderly, such as cardiovascular diseases and cancer, may even increase severity and case fatality (Cavellani et al., 2007).

The high proportion and death rate in people of withe race/colour can be mainly explained by the higher population of European descendants in Brazil's Southeast and South regions (IBGE, 2010). However, an important number of missing data regarding race/colour limits the validity and the interpretation of this information should be performed with caution.

We observed that the main conditions or causes of death associated with NCC-related deaths as underlying cause included diseases of the nervous and respiratory systems, corroborating findings from previous studies (Sorvillo et al., 2004; Townes et al., 2004; Santo, 2007; Sorvillo et al., 2007). Consistent with the clinical descriptions and natural history of disease, there was a large number of concurrent conditions directly related to complications of brain involvement, namely hydrocephalus, intracranial hypertension, cerebral oedema, stroke and epilepsy/convulsions (Sorvillo et al., 2004; Townes et al., 2004; Agapejev 2003; Santo, 2007; 
Sorvillo et al., 2007; Carabin et al., 2011). The presence of associated causes of death considered terminal conditions, such as respiratory failure, pneumonia, respiratory arrest and sepsis may reflect the severity of the NCC-related complications process leading to death (Santo, 2007). Considering deaths in which NCC was identified as an associated cause, the predominance of HIV/AIDS as underlying cause was similar to findings of a previous mortality study (Santo, 2007). HIV/AIDS can aggravate the condition of NCC patients (Delobel et al., 2004; Santo, 2007), but further studies are necessary to establish the effect of NCC-HIV co-infection in aggravating or deterioration of both diseases (Anand et al., 2014). Stroke, a relatively common but neglected complication of NCC, is caused by inflammatory occlusion of the arteries of the brain (Rocha et al., 2001; Santo, 2007).

The taeniasis/cysticercosis complex is not a compulsory notifiable disease and there is not a specific national control program in Brazil (Takayanagui and Leite, 2001; Agapejev, 2003). Although the Brazilian Ministry of Health recommends the implementation of compulsory notification of taeniasis/cysticercosis complex in endemic areas, only some states (Santa Catarina, Paraná, Minas Gerais and Mato Grosso do Sul) and the municipality of Ribeirão Preto (São Paulo state) have deployed taeniasis/cysticercosis control programs (Takayanagui et al., 1996; Agapejev, 2003). Consequently, data on incidence and prevalence of NCC remain widely unknown, and disease occurrence is most probably underestimated in Brazil (Agapejev, 2003). The implementation of appropriate surveillance mechanisms and a mandatory reporting system for taeniasis/cysticercosis complex throughout the national territory could provide more accurate epidemiological data on the population prevalence and would allow geographical mapping of the affected areas to improve effectiveness of surveillance and control measures (Takayanagui and Leite, 2001; Agapejev, 2003). Control measures should include free access to preventive chemotherapy, early diagnosis and treatment of taeniasis cases, improved pig husbandry practices, strict meat product inspection, and anthelmintic treatment and vaccination of pigs (WHO, 2002, 2010a; Croker et al., 2012). These specific control actions should be developed along with more general measures, such as improvements of living conditions, access to adequate water and sanitation, improved access to health care and health education (WHO, 2010a; Torres, 2015).

Our study has some limitations. Secondary data may present incomplete and biased information, despite the improved coverage and quality of SIM datasets during the past years (Martins-Melo et al., 2012a,b, 2014a). For example, an increasing trend may be caused partially by increased coverage and improvements of death records of SIM during the study period, as well as by improvement of access to health care services (Martins-Melo et al., 2014b). SIM coverage in 2011 was lowest in Maranhão state (79.1\%) in Northeast region and highest in the states of the Southeast and South regions, with $100 \%$ coverage (http://tabnet.datasus.gov. br/cgi/idb2012/a1801b.htm). Consequently, changes in mortality trends among regions should be interpreted with care. The underlying cause of death may have been encoded as a complication or aggravation associated with NCC (such as cerebral oedema, hydrocephalus and intracranial hypertension). We collected information based on multiple causes of death, rather than only the underlying cause, to reduce this error and to identify all death certificates in which NCC was mentioned in any field. In fact, an additional $32 \%$ of cases were identified by using multiple causes of death. However, it still can be assumed that the number of deaths by NCC has been underestimated to some extent. First, about $8 \%$ of cysticercosis-related deaths (ICD-10: B69) were recorded as unspecified cysticercosis (ICD-10: B69.9) (156/2007); a certain number of NCC may be included in this group, without being reported adequately. Second, diagnosis of NCC requires confirmation of infection through neuroimaging and serologic testing, biopsy or autopsy (Sorvillo et al., 2004, 2007). Some fatal NCC cases may thus not have been diagnosed, with consequent miscoding of NCC-related deaths as other conditions (Sorvillo et al., 2004).

Another limitation is related to the use of scan statistics, which has implications on results interpretation. The circular window imposed for scan space-time analysis to identify clusters may include places of low rates or with absence of deaths, if these places are surrounded by places characterized by high mortality rates (Lutambi et al., 2010; Shabani et al., 2010). In addition, the results produced are very sensitive to the parameter setting of the statistical program (Cheung et al., 2013).

Mortality data may be limited to identify specific areas of high transmission and endemicity of NCC, since most deaths may have been a result of infections acquired many years ago, and due to internal migration of infected people, the location of death not necessarily reflects the location of infection (Mendes et al., 2005; Martins-Melo et al., 2015).

\section{Conclusions}

NCC is an important but neglected and preventable cause of death in Brazil. As indicated by the analysis of multiple causes of death, NCC-related deaths may be largely underestimated in the country. Despite the decline of NCC-related mortality, this pattern was not observed in the regions with low rates and with worse socioeconomic conditions, such as the North and Northeast regions. Clusters of municipalities with high mortality rates were found mainly in states and regions considered highly endemic for disease. Specific public health measures including surveillance and control systems and compulsory notification for taeniasis/cysticercosis complex should be implemented throughout the country.

\section{Acknowledgements}

The authors thank the Coordenação de Aperfeiçoamento de Pessoal de Nível Superior (CAPES/Brazil) for granting a PhD Scholarship to FRM. JH is a class 1 research fellow at the Conselho Nacional de Desenvolvimento Científico e Tecnológico (CNPq/Brazil).

\section{Appendix A. Supplementary data}

Supplementary data associated with this article can be found, in the online version, at http://dx.doi.org/10.1016/j.actatropica.2015. 10.011 .

\section{References}

Australian Institute of Health Welfare, 2012. Multiple Causes of Death in Australia: An Analysis of All Natural and Selected Chronic Disease Causes of Death 1997-2007. AIHW, Canberra, Available from http://www.aihw.gov.au/ publication-detail/?id=10737422603 (accessed 20.10.13.).

Agapejev, S., 1996. Epidemiology of neurocysticercosis in Brazil. Rev. Inst. Med. Trop. Sao Paulo 38, 207-216.

Agapejev, S., 2003. [Clinical and epidemiological aspects of neurocysticercosis in Brazil: a critical approach]. Arq. Neuropsiquiatr. 61, 822-828.

Agapejev, S., 2011. Neurocysticercosis: the enigmatic disease. Cent. Nerv. Syst. Agents Med. Chem. 11, 261-284

Almeida, S.M., Torres, L.F.B., 2011. Neurocysticercosis-retrospective study of autopsy reports, a 17-year experience. J. Commun. Health 36, 698-702.

Anand, K.S., Wadhwa, A., Garg, J., Mahajan, R.K., 2014. HIV-associated neurocysticercosis. J. Int. Assoc. Provid. AIDS Care 14, 120-122.

Anselin, L., 1995. Local indicators of spatial association-LISA. Geogr. Anal. 27, 93-115.

Assunção, R.M., Barreto, S.M., Guerra, H.L., Sakurai, E., 1998. [Maps of epidemiological rates: a Bayesian approach]. Cad. Saude Publ. 14, 713-723.

Benedeti, M.R., Falavigna, D.L.M., Falavigna-Guilherme, A.L., Araújo, S.M., 2007. [Epidemiological and clinical profile of neurocysticercosis patients assisted by the Hospital Universitário Regional de Maringá, Paraná, Brazil]. Arq. Neuropsiquiatr. 65, 124-129.

Bhattarai, R., Budke, C., Carabin, H., 2013. The burden of cysticercosis. In: Sibat, H.F. (Ed.), Novel Aspects on Cysticercosis and Neurocysticercosis. InTech, Available 
from: http://www.intechopen.com/books/novel-aspects-on-cysticercosis-andneurocysticercosis/the-burden-of-cysticercosis (accessed 15.12.14.).

Brazilian Ministry of Health, 2001. Manual de procedimentos do Sistema de Informacões sobre Mortalidade. Brazilian Ministry of Health, Brasília.

Carabin, H., Ndimubanzi, P.C., Budke, C.M., Nguyen, H., Qian, Y., Cowan, L.D., Stoner, J.A., Rainwater, E., Dickey, M., 2011. Clinical manifestations associated with neurocysticercosis: a systematic review. PLoS Negl. Trop. Dis. 5, e1152.

Carpio, A., 2002. Neurocysticercosis: an update. Lancet Infect. Dis. 2, 751-762.

Cavellani, C.L., Faleiros, A.C.G., de Souza Lino, R., dos Reis, M.A., Teixeira, V.P.A., 2007. Cysticercosis in the elderly. Ann. Diagn. Pathol. 11, 330-333.

Cavellani, C.L., Corrêa, R.R.M., Ferraz, M.L.F., Rocha, L.P., Faleiros, A.C.G., Lino Junior, R.S., Reis, M.A., Teixeira, V.P.A., 2012. Influence of gender on cardiac and encephalic inflammation in the elderly with cysticercosis: a case control study. J. Trop. Med., 540858.

Chagas, M.G.L., D’Oliveira Júnior, A., Tavares-Neto, J., 2003. [Clinical aspects of neurocysticercosis at semi-desert region of Brazilian northeast]. Arq. Neuro-Psiquiatr. 61, 398-402.

Cheung, Y.T.D., Spittal, M.J., Williamson, M.K., Tung, S.J., Pirkis, J., 2013. Application of scan statistics to detect suicide clusters in Australia. PLoS One 8, e54168.

Chimelli, L., Lovalho, A.F., Takayanagui, O.M., 1998. [Neurocysticercosis: contribution of autopsies to consolidation of the compulsory notification in Ribeirão Preto-SP, Brazill. Arq. Neuropsiquiatr. 56, 577-584.

Cliff, A.D., Ord, J.K., 1981. Spatial Processes: Models \& Applications. Pion, London.

Coral-Almeida, M., Gabriël, S., Abatih, E.N., Praet, N., Benitez, W., Dorny, P., 2015. Taenia solium human cysticercosis: a systematic review of sero-epidemiological data from endemic zones around the world. PLoS Negl. Trop. Dis. 9, e0003919.

Coyle, C.M., Mahanty, S., Zunt, J.R., Wallin, M.T., Cantey, P.T., White Jr, A.C., O'Neal, S.E., Serpa, J.A., Southern, P.M., Wilkins, P., 2012. Neurocysticercosis: neglected but not forgotten. PLoS Negl. Trop. Dis. 6, e1500.

Croker, C., Redelings, M., Reporter, R., Sorvillo, F., Mascola, L., Wilkins, P., 2012. The impact of neurocysticercosis in California: a review of hospitalized cases. PLoS Negl. Trop. Dis. 6, e1480.

Del Brutto, O.H., 2012a. Neurocysticercosis in Western Europe: a re-emerging disease? Acta Neurol. Belg. 112, 335-343.

Del Brutto, O.H., 2012b. A review of cases of human cysticercosis in Canada. Can. J. Neurol. Sci. 39, 319-322.

Del Brutto, O.H., 2014. Neurocysticercosis. Neurohospitalist 4, 205-212.

Del Brutto, O.H., García, E., Talamas, O., Sotelo, J., 1988. Sex-related severity of inflammation in parenchymal brain cysticercosis. Arch. Intern. Med. 148, 544-546.

Delobel, P., Signate, A., El Guedj, M., Couppie, P., Gueye, M., Smadja, D., Pradinaud, R., 2004. Unusual form of neurocysticercosis associated with HIV infection. Eur. J. Neurol. 11, 55-58.

Fleury, A., Dessein, A., Preux, P.M., Dumas, M., Tapia, G., Larralde, C., Sciutto, E., 2004. Symptomatic human neurocysticercosis. J. Neurol. 251, 830-837.

Flisser, A., Sarti, E., Lightowlers, M., Schantz, P., 2003. Neurocysticercosis: regional status, epidemiology, impact and control measures in the Americas. Acta Trop. $87,43-51$.

Flisser, A., Correa, D., 2010. Neurocysticercosis may no longer be a public health problem in Mexico. PLoS Negl. Trop. Dis. 4, e831.

Freitas, F.I.D.S., Meza-Lucas, A., Lima, C.B., Costa, W.D., Melo, A., 2005. [Cysticercosis research in epileptic patients dwelling in towns of the western Cariri in the State of Paraíba, Brazil]. Arq. Neuropsiquiatr. 63, 656-660.

Gonzales, I., Miranda, J.J., Rodriguez, S., Vargas, V., Cjuno, A., Smeeth, L., Gonzalez, A.E., Tsang, V.C., Gilman, R.H., Garcia, H.H., 2015. Seizures, cysticercosis and rural-to-urban migration: the PERU MIGRANT study. Trop. Med. Int. Health 20, $546-552$.

Grazziotin, A.L., Fontalvo, M.C., Santos, M.B., Monego, F., Grazziotin, A.L., Kolinski, V.H., Bordignon, R.H., Biondo, A.W., Antoniuk, A., 2010. Epidemiologic pattern of patients with neurocysticercosis diagnosed by computed tomography in Curitiba, Brazil. Arq. Neuropsiquiatr. 68, 269-272.

Hotez, P.J., Fujiwara, R.T., 2014. Brazil's neglected tropical diseases: an overview and a report card. Microbes Infect. 16, 601-606.

Instituto Brasileiro de Geografia e Estatística-IBGE, 2010. Síntese dos Indicadores Sociais 2010. IBGE, Rio de Janeiro, Available from: http://www.ibge.gov.b home/estatistica/populacao/condicaodevida/indicadoresminimos/ sinteseindicsociais2010/SIS_2010.pdf (accessed 23.01.15.).

Kim, H.J., Fay, M.P., Feuer, E.J., Midthune, D.N., 2000. Permutation tests for joinpoint regression with applications to cancer rates. Stat. Med. 15, 335-351

Kulldorff, M., 1997. A spatial scan statistic. Commun. Stat. Theory Methods 26, 1481-1496.

Lindoso, J.A.L., Lindoso, A.A.B.P., 2009. Neglected tropical diseases in Brazil. Rev. Inst. Med. Trop. Sao Paulo 51, 247-253.

Lino-Junior, R.S., Faleiros, A.C., Vinaud, M.C., Oliveira, F.A., Guimarães, J.V., Reis, M.A., Teixeira, V.P., 2007. Anatomopathological aspects of neurocysticercosis in autopsied patients. Arq. Neuropsiquiatr. 65, 87-91.

Lutambi, A.M., Alexander, M., Charles, J., Mahutanga, C., Nathan, R., 2010. Under-f Ive Mortality: Spatial-temporal Clusters in Ifakara HDSS in South-Eastern Tanzania. Glob. Health Action 3.
Martins-Melo, F.R., Alencar, C.H., Ramos Jr., A.N., Heukelbach, J., 2012a

Epidemiology of mortality related to Chagas' disease in Brazil, 1999-2007. PLoS Negl. Trop. Dis. 6, e1508.

Martins-Melo, F.R., Ramos Jr, A.N., Alencar, C.H., Lange, W., Heukelbach, J., 2012b. Mortality of Chagas' disease in Brazil: spatial patterns and definition of high-risk areas. Trop. Med. Int. Health 17, 1066-1075.

Martins-Melo, F.R., da Silveira Lima, M., Ramos Jr, A.N., Alencar, C.H., Heukelbach, J., 2014a. Mortality and case fatality due to visceral leishmaniasis in Brazil: a nationwide analysis of epidemiology, trends and spatial patterns. PLoS One 9, e93770.

Martins-Melo, F.R., Pinheiro, M.C.C., Ramos, A.N., Alencar, C.H., de Moraes Bezerra, F.S., Heukelbach, J., 2014b. Trends in schistosomiasis-related mortality in Brazil, 2000-2011. Int. J. Parasitol. 44, 1055-1062.

Martins-Melo, F.R., Pinheiro, M.C.C., Ramos Jr, A.N., Alencar, C.H., Bezerra, F.S.M., Heukelbach, J., 2015. Spatiotemporal patterns of schistosomiasis-related deaths, Brazil, 2000-2011. Emerg. Infect. Dis. 10, 1820-1823.

Mendes, E.C., Silva, S.S., Fonseca, E.A.L.T., Souza, H.R.R., Carvalho, R.W., 2005. [Human neurocysticercosis in Baixada Fluminense, Rio de Janeiro State, Brazil]. Arq. Neuro-Psiquiatr. 63, 1058-1062.

Montemor Netto, M.R., Gasparetto, E.L., Faoro, L.N., Reis Filho, J.S., Toni, G.S.D., Carvalho Neto, A.D., Torres, L.F.B., 2000. [Neurocysticercosis: a clinical and pathological study of 27 necropsied cases]. Arq. NeuroPsiquiatr. 58, 883-889.

Mwape, K.E., Phiri, I.K., Praet, N., Speybroeck, N., Muma, J.B., Dorny, P., Gabriël, S., 2013. The incidence of human cysticercosis in a rural community of Eastern Zambia. PLoS Negl. Trop. Dis. 7, e2142.

Nash, T.E., Mahanty, S., Garcia, H.H., 2013. Neurocysticercosis-more than a neglected disease. PLoS Negl. Trop. Dis 7, e1964.

Pfuetzenreiter, M.R., Avila-Pires, F.D., 1999. [Clinical manifestations in patients with computerized tomography diagnosis of neurocysticercosis]. Arq. Neuro-Psiquiatr. 57, 653-658.

Pfuetzenreiter, M.R., Pires, F.D.A., 2000. [Epidemiology of teniasis/cysticercosis by Taenia solium and Taenia saginata]. Cienc. Rural 30, 541-548.

Praet, N., Speybroeck, N., Rodriguez-Hidalgo, R., Benitez-Ortiz, W., Berkvens, D., Brandt, J., Saegerman, C., Dorny, P., 2010. Age-related infection and transmission patterns of human cysticercosis. Int. J. Parasitol. 40, 85-90.

Redelings, M.D., Sorvillo, F., Simon, P., 2006. A comparison of underlying cause and multiple causes of death: US vital statistics, 2000-2001. Epidemiology 17, 100-103.

Rocha, M.S., Brucki, S.M., Ferraz, A.C., Piccolo, A.C., 2001. [Cerebrovascular disease and neurocysticercosis]. Arq. Neuropsiquiatr. 59, 778-783.

Santo, A.H., 2007. Cysticercosis-related mortality in the State of São Paulo, Brazil 1985-2004: a study using multiple causes of death. Cad. Saude Publ. 23. 2917-2927.

Secka, A., Grimm, F., Marcotty, T., Geysen, D., Niang, A.M., Ngale, V., Boutche, L., Van Marck, E., Geerts, S., 2011. Old focus of cysticercosis in a senegalese village revisited after half a century. Acta Trop. 119, 199-202.

Shabani, J., Lutambi, A.M., Mwakalinga, V., Masanja, H., 2010. Clustering of under-five mortality in Rufiji health and demographic surveillance system in rural Tanzania. Glob. Health Action 3.

Shandera, W.X., White Jr, A.C., Chen, J.C., Diaz, P., Armstrong, R., 1994. Neurocysticercosis in Houston, Texas: a report of 112 cases. Medicine (Baltimore) 73, 37-52.

Sorvillo, F.J., DeGiorgio, C., Waterman, S.H., 2007. Deaths from cysticercosis, United States. Emerg. Infect. Dis. 13, 230-235.

Sorvillo, F.J., Portigal, L., DeGiorgio, C., Smith, L., Waterman, S.H., Berlin, G.W., Ash, L.R., 2004. Cysticercosis-related deaths, California. Emerg. Infect. Dis. 10, $465-469$.

Takayanagui, O.M., Castro e Silva, A.A., Santiago, R.C., Odashima, N.S., Terra, V.C., Takayanagui, A.M., 1996. [Compulsory notification of cysticercosis in Ribeiräo Preto-SP, Brazil]. Arq. Neuropsiquiatr. 54, 557-564.

Takayanagui, O.M., Leite, J.P., 2001. Neurocysticercosis. Rev. Soc. Bras. Med. Trop. 34, 283-290.

Townes, J.M., Hoffmann, C.J., Kohn, M.A., 2004. Neurocysticercosis in Oregon, 1995-2000. Emerg. Infect. Dis. 10, 508-510.

Torres, J.R., 2015. Cysticercosis disease burden in Latin America. In: Franco-Paredes, C., Santos-Preciado, J.I. (Eds.), Neglected Tropical Diseases-Latin America and the Caribbean. Springer, Vienna, pp. 225-232.

Wallin, M.T., Kurtzke, J.F., 2004. Neurocysticercosis in the United States review of an important emerging infection. Neurology 63, 1559-1564.

WHO, 2002. Control of neurocysticercosis: peport by the secretariat. In: Fifty-fifth World Health Assembly; Provisional Agenda Item 13.18. World Health Organization, Washington, DC, Report no. A55/23.

WHO, 2010a. First WHO Report on Neglected Tropical Diseases: Working to Overcome the Global Impact of Neglected Tropical Diseases. World Health Organization, Geneva.

WHO, 2010b. Statistical Classification of Diseases and Related Health Problems (ICD): 10th Revision. Version 2010. World Health Organization, Geneva, Available from: http://apps.who.int/classifications/apps/icd/icd10online/ (accessed 15.10.2013.). 